\title{
Extreme negative mechanical phenomena in the zinc and cadmium anhydrous metal oxalates and lead oxalate dihydrate
}

Francisco Colmenero $^{1} \cdot$ Vicente Timón $^{1}$

\begin{abstract}
The crystal structures and elastic properties of the anhydrous zinc and cadmium oxalates and lead oxalate dihydrate are determined using rigorous first-principles solid-state methods. The three materials are shown to display negative Poisson's ratios (NPR) and to exhibit the negative linear compressibility (NLC) phenomenon. Anhydrous zinc and cadmium oxalates display NLC for a very wide range of external pressures applied in the direction of minimum compressibility in the ranges -1.3 to $5.5 \mathrm{GPa}$ and -1.2 to $2.7 \mathrm{GPa}$, respectively. The increase of volume in both materials is substantial for pressures larger than 3.6 and $1.8 \mathrm{GPa}$ and the compressibilities become -70.1 and $-67.0 \mathrm{TPa}^{-1}$ for pressures of 5.2 and $2.6 \mathrm{GPa}$, respectively. The increase of volume is so drastic that these materials become unstable for pressures larger than 5.5 and $2.7 \mathrm{GPa}$. Lead oxalate dihydrate also displays NLC along the direction of minimum Poisson's ratio for negative pressures in the range -0.05 to $-0.08 \mathrm{GPa}$ and undergoes a pressure induced phase transition for relatively low external pressures of the order of 0.1 GPa. The presence of NPR and NLC phenomena in these three materials together with the previous finding of these phenomena for silver oxalate, strongly suggest that other metal oxalate materials could also exhibit an extremely anomalous mechanical behavior.
\end{abstract}

\section{Introduction}

In recent works [1-7], the elastic behavior of small organic acids and metal-organic materials in the solid-state was studied using rigorous first-principles solid-state methods based in Density Functional Theory (DFT) using plane wave basis sets and pseudopotentials to describe the internal electrons [8]. Accurate descriptions of the elastic properties of these materials were obtained by means of extended computational treatments. It was shown that these materials display negative values of the Poisson's ratio (NPR) [9-14] and exhibit the important negative linear compressibility (NLC) phenomenon [15-20]. In particular, anhydrous silver oxalate, was revealed be strongly auxetic [21-22] and to exhibit the most extreme form of the negative linear compressibility phenomenon found up to date [7]. For this reason, the study of the elastic properties of silver oxalate was extended to other metal oxalates as the zinc and cadmium anhydrous oxalates, $\mathrm{ZnC}_{2} \mathrm{O}_{4}$ and $\mathrm{CdC}_{2} \mathrm{O}_{4}$, and

\footnotetext{
* Francisco Colmenero

E-mail address: francisco.colmenero@iem.cfmac.csic.es ORCID ID: https://orcid.org/0000-0003-3418-0735

${ }^{1}$ Department of Molecular Physics Instituto de Estructura de la Materia (IEM-CSIC), 28006 Madrid, Spain.
}

lead oxalate dihydrate, $\mathrm{PbC}_{2} \mathrm{O}_{4} \cdot 2 \mathrm{H}_{2} \mathrm{O}$, with the purpose of analyzing the possible presence of extreme negative mechanical phenomena in other materials of the same chemical group. As it will be shown, the results reported in the present study confirm this hypothesis.

The anhydrous metal oxalates [23] are especially relevant in material science because these materials have important applications in nanomaterials technologies [24-41]. The controlled thermal decomposition process of metal oxalates [29-41] produces nanoparticles of metallic or metal oxide compounds which may be incorporated into a large series of technological and commercial products. Important examples are their use in the production of coatings, pigments, absorbing and shielding materials, nanofibers, electrodes, inkjet thin films, first aid bandages plastics, soaps, skin care products and textiles [24-31] acquiring desirable material properties. In order to obtain antimicrobial effects, metallic ions, as zinc and silver, are incorporated at the stage of synthesis to dental composites and artificial bone materials [42]. Outstanding corrosion protection properties are attained by means of the deposition of zinc oxalate coatings [43]. Anhydrous cadmium oxalate is also employed for obtaining ferrite compounds [44], magnetic materials [45], and complex salts in sol-gel reactions [46-50] and is employed as dopant for obtaining mixed oxide systems [51]. Anhydrous metal oxalates are also useful in thick-film applications [52, 31], as anode materials for lithium-ion batteries [53-56] and as dopants for improving the functionality of conducting polymers and nanomaterials [57]. Because the decomposition of some metal oxalate materials may also be activated mechanically [58-60], it is remarkable that the elastic properties of these materials have not been hitherto reported and their anomalous mechanical behavior has not been noticed. While the metal oxalate pressure induced decomposition was produced by ball milling [58-60], the fact that single crystals become unstable under pressure should be the underlying physical reason for the mechanical decomposition of the zinc and cadmium oxalates. The main aim of this work is to show that the elastic behavior of the zinc and cadmium anhydrous divalent metal oxalates is, as that of the silver anhydrous monovalent metal oxalate [7], very extreme and, therefore, their elastic properties are potentially useful in a large series of technological applications. Moreover, the elastic behavior of the zinc and cadmium oxalates is shown to be analogous suggesting a common mechanical performance of the group of anhydrous divalent metal oxalate materials having structures based in chains formed by alternate oxalate and metal-oxygen polyhedra fragments. This kind of structure- 
function relationships are very important in materials science. They may be used to understand the origin of the special properties of some compounds and to anticipate their existence in structurally related materials with very different compositions.

NPR and NLC materials have enhanced material properties resulting exclusively from their elastic behavior [1]. These properties make them appropriate for an immense range of applications as in textile [61-65] and automotive industries [66], personnel protection [67], biomedicine [68-69], aerospace and defense [70-73], and in many commercial applications requiring filters, sieves, sensors, packaging and insulation [17, 74-75]. In particular, NLC materials have been utilized to develop ultrasensitive pressure-sensing devices, pressure driven actuators, optical telecommunication cables, artificial muscles, nextgeneration body armor and in biomedical uses [1, 17-18]. Natural NLC materials are very infrequent [20]. Although synthetic procedures and design approaches have been formulated to obtain materials showing specific elastic properties [1, 19, 76-79], the magnitude of the NLC and the range of external pressures for which these natural and synthetic materials show NLC are frequently too small to be useable in practice. The purpose of this and the previous studies [1-7], is to examine the occurrence of negative mechanical phenomena in organic materials because these effects have been studied only occasionally for this class of compounds, exposing a substantial gap in their research. The relevance of this research derives from the wide range of potential applications of these materials, the great versatility of organic synthesis and the wide variety of organic crystalline structure types which may show these effects.

This paper is organized as follows. In the Methods Section, the first-principles solid-state methodology used in this work is described. The main results are reported in the following Section. The first Subsection provides the calculated crystal structures and their associated X-ray powder patterns. The computed elastic properties are then given and their dependence on the orientation of the applied strain is studied. The presence of the NPR and NLC negative mechanical phenomena in the considered materials is also shown. In the section of Discussion a detailed analysis of the results is given. In this section, the deformation of the crystal structures under pressure at the basis of the NLC effect in these materials is also studied. Finally, in the last section, the conclusions of this work are presented.

\section{Methods}

\section{Crystal structure optimization}

The crystal structures of the anhydrous zinc and cadmium oxalates and lead oxalate dihydrate were modeled using first-principles solid-state methods based in DFT using plane wave basis sets and pseudopotentials [8]. The energydensity functionals employed in this study were the specialized version of Perdew-Burke-Ernzerhof (PBE) functional [80] for solid materials, PBEsol [81], for the two anhydrous materials and the PBE functional [80] supplemented with Grimme empirical dispersion correction [82] for the dihydrate. The introduction of dispersion corrections improved substantially the description of the hydrogen bonding structure present in the unit cell of lead oxalate dihydrate. These density functionals are implemented in CASTEP computer program [83] a module of the Materials Studio program suite [84]. The pseudopotentials used for $\mathrm{C}, \mathrm{O}, \mathrm{H}, \mathrm{Zn}, \mathrm{Cd}$ and $\mathrm{Pb}$ atoms were standard norm-conserving pseudopotentials [85] given in CASTEP code. The representative volume elements of the materials considered are the corresponding unit cells. Periodic boundary conditions are applied in the calculations. These boundary conditions are not imposed as constrains in the variational procedures since the electron density of the material is represented in terms of periodic functions with the periodicity of the material considered and, therefore, the boundary conditions are satisfied by construction.

The Broyden-Fletcher-Goldfarb-Shanno (BFGS) technique [8, 86] was employed to optimize the atomic positions and unit cell lattice parameters of these materials. The geometries were optimized using a convergence threshold on atomic forces of $0.01 \mathrm{eV} / \AA$. The calculation parameters, the kinetic energy cuff-off $(\varepsilon)$ and $k$-mesh [87], utilized in the calculations are given in Table S.1 of the Supplementary Material. It must be emphasized that the selected parameters are larger than those usually used in this kind of studies in order to attain reliable crystal structures, energies and values of the computed elastic properties. From the optimized structures, the X-ray diffraction powder patterns were determined [88] using the REFLEX module included in the Materials Studio suite [84].

\section{Determination of elastic tensors}

The stiffness tensor needed to calculate the elastic properties of the materials considered was obtained for the optimized crystal structures from stress-strain relationships employing the finite deformation technique [89]. The first and second derivatives of the bulk modulus with respect to pressure were determined by performing fits of the unit cell volumes and associated pressures to a fourth-order BirchMurnahan [90] equation of state (EOS). The unit cell volumes in the neighborhood of the equilibrium structures were calculated by optimizing the crystalline structures under the effect of seventeen different applied isotropic pressures within the range from -1.0 to $11.0 \mathrm{GPa}$. The fits of the pressure-volume data to the chosen EOS were carried out utilizing the EOSFIT 5.2 computer program [91]. The three-dimensional representations of the elastic properties of the materials considered as a function of the orientation of the applied strain were obtained using the ElAM program [92]. Finally, it should be noticed that the optimized crystal structures under pressure were also determined using the BFGS algorithm. 
Table 1. Lattice parameters of $\mathrm{ZnC}_{2} \mathrm{O}_{4}, \mathrm{CdC}_{2} \mathrm{O}_{4}$ and $\mathrm{PbC}_{2} \mathrm{O}_{4} \cdot 2 \mathrm{H}_{2} \mathrm{O}$.

\begin{tabular}{ccccccccc}
\hline Parameter & $\boldsymbol{a}(\AA)$ & $\boldsymbol{b}(\AA)$ & $\boldsymbol{c}(\AA)$ & $\boldsymbol{\alpha}(\mathbf{d e g})$ & $\boldsymbol{\beta}(\mathbf{d e g})$ & $\boldsymbol{\gamma}(\mathbf{d e g})$ & Vol. $\left(\AA^{\mathbf{3}}\right)$ & Dens. $\left(\mathbf{g} / \mathbf{c m}^{\mathbf{3}}\right)$ \\
\hline DFT & 5.7942 & 5.1505 & 5.3487 & 90.0 & 113.65 & 90.0 & 146.2142 & 3.484 \\
Exp. [93] & 5.831 & 5.123 & 5.331 & 90.0 & 113.20 & 90.0 & 146.3712 & 3.481 \\
\hline \multicolumn{7}{c}{ Cadmium oxalate } \\
\hline DFT & 5.8453 & 5.3340 & 5.8572 & 90.0 & 114.21 & 90.0 & 166.5586 & 3.997 \\
Exp. [94] & 5.826 & 5.252 & 5.832 & 90.0 & 113.86 & 90.0 & 163.1976 & 4.079 \\
\hline \multicolumn{7}{c}{ Lead oxalate dihydrate } \\
\hline DFT & 9.3558 & 8.0261 & 7.8393 & 90.0 & 90.0 & 90.0 & 588.6576 & 3.738 \\
Exp. [95] & 9.053 & 8.036 & 7.834 & 90.0 & 90.0 & 90.0 & 569.9228 & 3.861 \\
\hline
\end{tabular}

(a) $\mathrm{ZnC}_{2} \mathrm{O}_{4}$

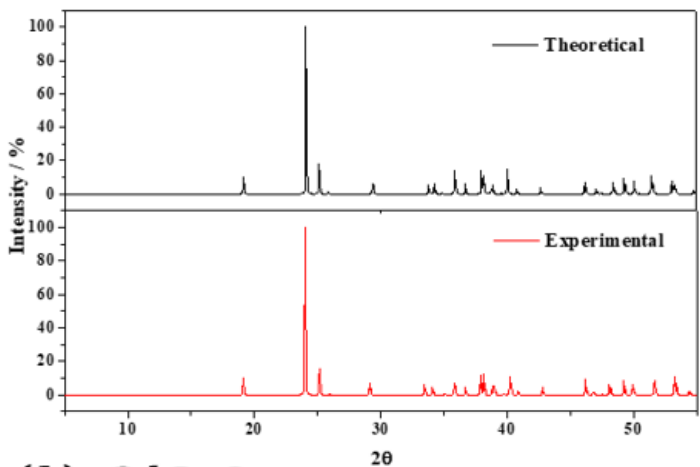

(b) $\mathrm{CdC}_{2} \mathrm{O}_{4}$

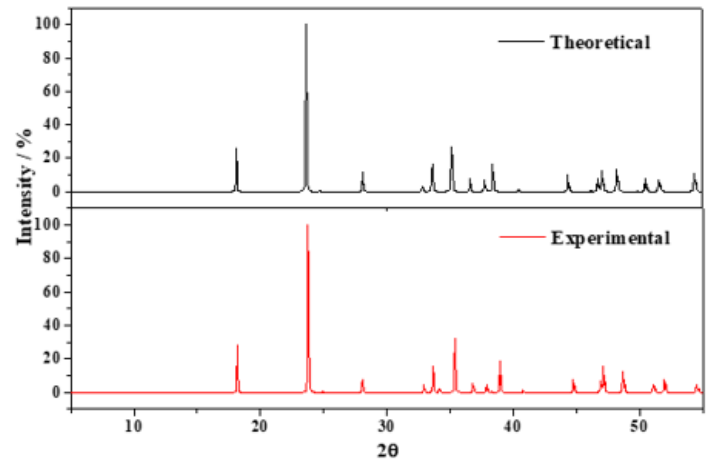

(c) $\mathrm{PbC}_{2} \mathrm{O}_{4} \cdot 2 \mathrm{H}_{2} \mathrm{O}$

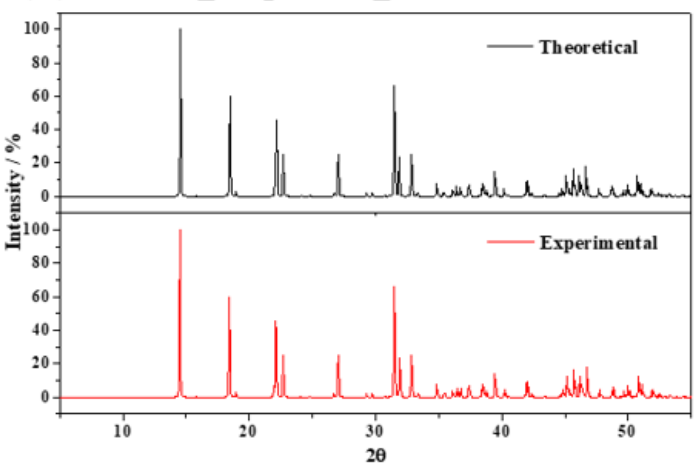

Fig. 1. X-ray powder diffractograms of the anhydrous zinc and cadmium oxalates and lead oxalate dihydrate determined from the calculated and experimental [93-95] geometries using $\mathrm{CuK}_{\alpha}$ radiation.

\section{Results}

\section{Crystal structures}

The calculated lattice parameters of the crystal structures of the zinc and cadmium oxalates and lead oxalate dihydrate are given in Table 1, where they are compared with the corresponding experimental data [93-95]. The polymorphic form of $\mathrm{CdC}_{2} \mathrm{O}_{4}$ studied in this paper is the ordered $\beta$ form $[94,96]$. The X-ray powder diffraction patterns of these materials were determined from the optimized and experimental crystal structures and are plotted in Fig. 1. The computed crystal structures of the zinc and cadmium oxalates and lead oxalate dihydrate are shown in Fig. 2. In this figure the atom labelling convention employed in this work for the atoms in the corresponding structures is also displayed.

\section{Elastic properties}

The number of non-vanishing elements of the stiffness tensor for materials having monoclinic (anhydrous zinc and cadmium oxalates) and orthorhombic (lead oxalate dihydrate) space symmetries are 13 and 9, respectively [97]. The calculated stiffness matrices, $C_{i j}$, for the materials considered are reported in Table 2.

The elastic properties of the polycrystalline forms of the considered materials were determined from the computed stiffness tensor elements utilizing the Voigt [98], Reuss [99] and Hill [100] approaches. As in previous studies [1-2, 6-7, 101-106], the Reuss approximation was selected as the best approach because it afforded the best comparison of the results for the calculated bulk modulus with the single crystal bulk modulus determined from the EOS. The calculated elastic properties are reported in Table 3 and the values of the bulk moduli and their first and second pressure derivatives calculated from the EOS are shown in Table 4. 
(a) $\mathrm{ZnC}_{2} \mathrm{O}_{4}$

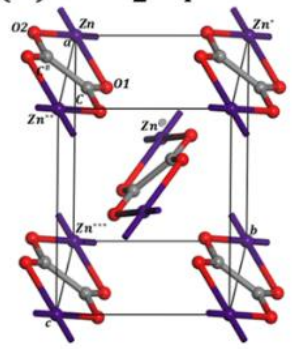

(b) $\mathrm{CdC}_{2} \mathrm{O}_{4}$

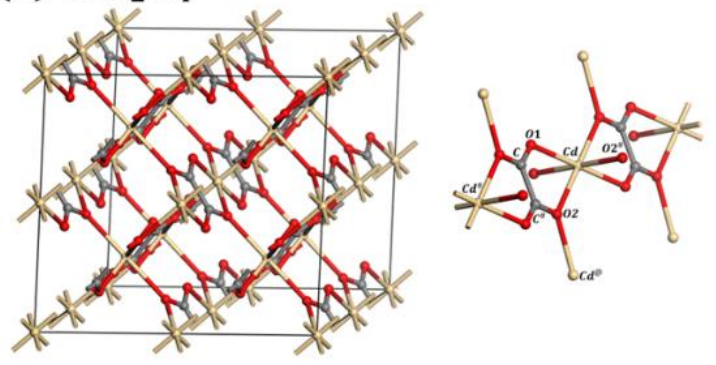

(c) $\mathrm{PbC}_{2} \mathrm{O}_{4} \cdot 2 \mathrm{H}_{2} \mathrm{O}$

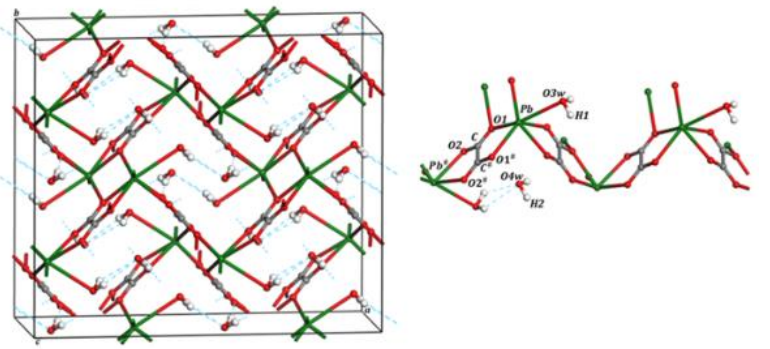

Fig. 2. Computed crystal structures of $\mathrm{ZnC}_{2} \mathrm{O}_{4}, \mathrm{CdC}_{2} \mathrm{O}_{4}$ and $\mathrm{PbC}_{2} \mathrm{O}_{4} \cdot 2 \mathrm{H}_{2} \mathrm{O}$ : (a) View of a single unit cell of $\mathrm{ZnC}_{2} \mathrm{O}_{4}$ from [001] crystallographic direction; (b) View of a $2 \times 2 \times 2$ supercell of $\mathrm{CdC}_{2} \mathrm{O}_{4}$ from [001] direction; (c) View of a $2 \times 2 \times 1$ supercell of $\mathrm{PbC}_{2} \mathrm{O}_{4} \cdot 2 \mathrm{H}_{2} \mathrm{O}$ from [001] direction; The images (b) and (c) are accompanied by pictures showing isolated cadmium and lead oxalate chains in which the atom labelling convention used is displayed. Color codes: C-grey; O-red; H-white; Zn-purple; Cdclear brown; Pb-green.

Table 2. Computed elastic constants of $\mathrm{ZnC}_{2} \mathrm{O}_{4}, \mathrm{CdC}_{2} \mathrm{O}_{4}$ and $\mathrm{PbC}_{2} \mathrm{O}_{4} \cdot 2 \mathrm{H}_{2} \mathrm{O}$. All the values are given in GPa.

\begin{tabular}{cccc}
\hline $\boldsymbol{i j}$ & $\begin{array}{c}\text { Zinc } \\
\text { oxalate }\end{array}$ & $\begin{array}{c}\text { Cadmium } \\
\text { oxalate }\end{array}$ & $\begin{array}{c}\text { Lead oxalate } \\
\text { dihydrate }\end{array}$ \\
\hline 11 & 59.72 & 47.60 & 33.65 \\
22 & 43.30 & 45.67 & 23.92 \\
33 & 279.86 & 231.98 & 54.22 \\
44 & 24.38 & 19.13 & 7.12 \\
55 & 30.20 & 22.30 & 5.11 \\
66 & 56.43 & 53.64 & 21.66 \\
12 & 23.50 & 29.77 & 16.44 \\
13 & 47.00 & 41.73 & 7.30 \\
15 & -6.31 & -7.78 & 0.0 \\
23 & 32.66 & 31.20 & 6.12 \\
25 & -2.12 & -6.28 & 0.0 \\
35 & -22.72 & -16.96 & 0.0 \\
46 & 0.72 & -4.53 & 0.0 \\
\hline
\end{tabular}

Table 3. Calculated elasticity properties of $\mathrm{ZnC}_{2} \mathrm{O}_{4}, \mathrm{CdC}_{2} \mathrm{O}_{4}$ and $\mathrm{PbC}_{2} \mathrm{O}_{4} \cdot 2 \mathrm{H}_{2} \mathrm{O}$. The values of the bulk, shear and Young moduli $(B, G$ and $E)$ are given in in GPa.

\begin{tabular}{ccccc}
\hline Property & $\begin{array}{c}\text { Zinc } \\
\text { oxalate }\end{array}$ & $\begin{array}{c}\text { Cadmium } \\
\text { oxalate }\end{array}$ & $\begin{array}{c}\text { Lead } \\
\text { oxalate } \\
\text { dihydrate }\end{array}$ \\
\hline $\boldsymbol{B}$ & Bulk modulus & 35.87 & 35.85 & 17.99 \\
$\boldsymbol{G}$ & Shea modulus & 26.18 & 18.84 & 8.32 \\
$\boldsymbol{E}$ & Young modulus & 63.17 & 48.10 & 21.63 \\
$\boldsymbol{v}$ & Poisson's ratio & 0.21 & 0.28 & 0.30 \\
$\boldsymbol{D}$ & Ductility index & 1.37 & 1.90 & 2.16 \\
$\boldsymbol{H}$ & Hardness index & 6.35 & 2.25 & 0.20 \\
$\boldsymbol{A}^{\boldsymbol{U}}$ & Anisotropy index & 3.63 & 4.63 & 2.41 \\
\hline
\end{tabular}

Table 4. Calculated first and second bulk modulus pressure derivatives derived from the EOS for $\mathrm{ZnC}_{2} \mathrm{O}_{4}, \mathrm{CdC}_{2} \mathrm{O}_{4}$ and $\mathrm{PbC}_{2} \mathrm{O}_{4} \cdot 2 \mathrm{H}_{2} \mathrm{O}$. The bulk moduli computed from the stiffness tensor elements are given in the last row for comparison.

\begin{tabular}{cccc}
\hline Property & $\begin{array}{c}\text { Zinc } \\
\text { oxalate }\end{array}$ & $\begin{array}{c}\text { Cadmium } \\
\text { oxalate }\end{array}$ & $\begin{array}{c}\text { Lead oxalate } \\
\text { dihydrate }\end{array}$ \\
\hline \multicolumn{4}{c}{ EOS } \\
\hline $\boldsymbol{B}(\boldsymbol{G P a})$ & $42.56 \pm 1.51$ & $38.94 \pm 1.06$ & $17.63 \pm 3.06$ \\
$\boldsymbol{B}^{\prime}$ & $3.35 \pm 1.31$ & $7.96 \pm 1.10$ & $1.75 \pm 0.88$ \\
$\boldsymbol{B}^{\prime \prime}\left(\boldsymbol{G P a} \boldsymbol{a}^{-1}\right)$ & $1.03 \pm 0.36$ & $-1.24 \pm 0.63$ & $5.51 \pm 2.74$ \\
$\boldsymbol{\chi}^{\mathbf{2}}$ & 0.010 & 0.060 & 0.056 \\
\hline \multicolumn{4}{c}{ Stiffness tensor } \\
\hline $\boldsymbol{B}(\boldsymbol{G P a})$ & $35.87 \pm 1.31$ & $35.85 \pm 0.50$ & $17.99 \pm 1.74$ \\
\hline
\end{tabular}

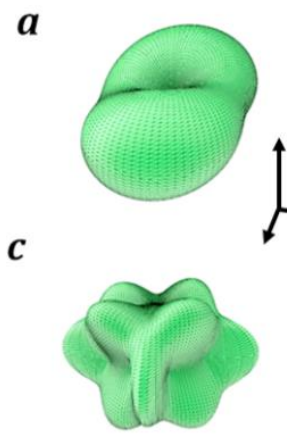

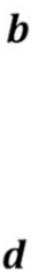

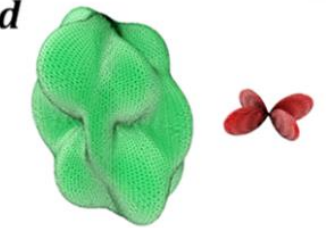

Fig. 3. Elastic properties of anhydrous zinc oxalate as a function of the orientation of the applied strain: (a) Compressibility; (b) Young modulus; (c) Maximum shear modulus; (d) Surfaces of minimum (red) and maximum (green) Poisson's ratio. The maximum values of the compressibility, Young modulus, shear modulus and Poisson's ratio are 17.73 $\mathrm{TPa}^{-1}, 244.01 \mathrm{GPa}, 56.44 \mathrm{GPa}$ and 0.62 , respectively.

Elastic properties as a function of the orientation of the applied strain

The spatial representations of the elastic properties of the materials under study as a function of the orientation of the applied strain are shown in Fig. 3, Fig. 4 and Fig 5. They were obtained using the ElAM computer program [92]. For the case of the shear modulus and Poisson's ratio, depending on two directions, the subfigures (c) and (d) provide representations of the surfaces of maximum $G$ and $v$. These 
surfaces are formed with the maximum values of these properties for a given direction of the longitudinal strain and all possible transverse directions [92]. The surfaces of minimum Poison's ratio are also given in Figs. 3(d), 4(d) and 5(d). As may be observed, the three considered materials display negative values of the minimum Poisson's ratio. The precise values of the minimum and maximum values of Poisson's ratios together with the associated longitudinal and transverse directions are reported in Table 5.
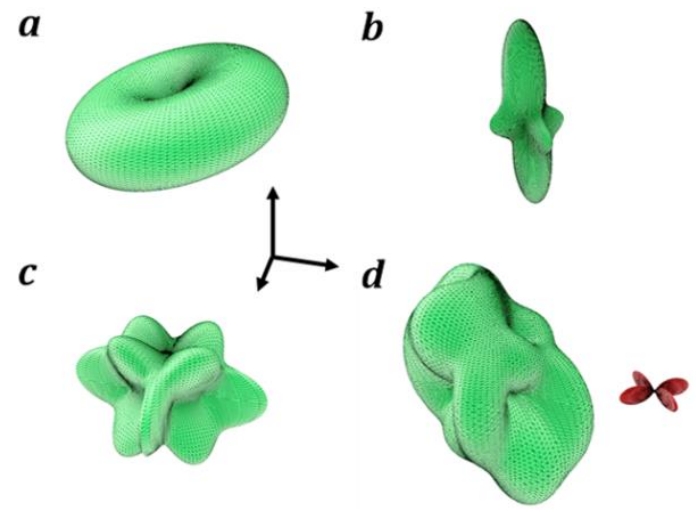

Fig. 4. Elastic properties of anhydrous cadmium oxalate as a function of the orientation of the applied strain: (a) Compressibility; (b) Young modulus; (c) Maximum shear modulus; (d) Surfaces of minimum (red) and maximum (green) Poisson's ratio. The maximum values of the compressibility, Young modulus, shear modulus and Poisson's ratio are 14.48 $\mathrm{TPa}^{-1}, 197.26 \mathrm{GPa}, 33.85 \mathrm{GPa}$ and 0.79 , respectively. a

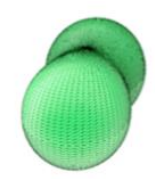

b

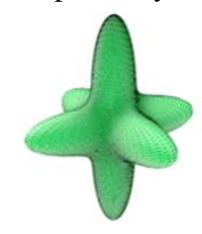

c

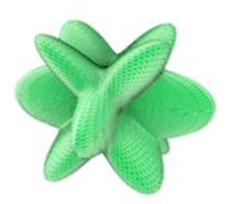

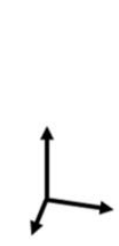

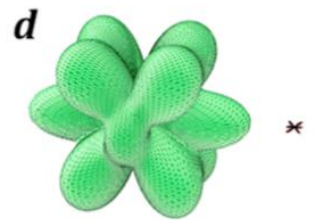

Fig. 5. Elastic properties of lead oxalate dihydrate as a function of the orientation of the applied strain: (a) Compressibility; (b) Young modulus; (c) Maximum shear modulus; (d) Surfaces of minimum (red) and maximum (green) Poisson's ratio. In this case, the surface of minimum $v$ is very small. The maximum values of the compressibility, Young modulus, shear modulus and Poisson's ratio are $30.02 \mathrm{TPa}^{-1}, 52.23 \mathrm{GPa}, 21.66 \mathrm{GPa}$ and 0.67 .

Unit cell volumes and lattice parameters as a function of external applied pressures

In order to study the negative linear compressibility phenomena in $\mathrm{ZnC}_{2} \mathrm{O}_{4}, \mathrm{CdC}_{2} \mathrm{O}_{4}$ and $\mathrm{PbC}_{2} \mathrm{O}_{4} \cdot 2 \mathrm{H}_{2} \mathrm{O}$ and to analyze their deformation under pressure, the crystal structures of these materials were optimized under the effect of different external pressures. The computed unit cell volumes and lattice parameters of anhydrous zinc oxalate for sixteen different external pressures directed along the minimum compressibility direction, $U_{\min }^{C}=(-0.16,0.0$, 0.99 ), are given in Table S.2 of the Supplementary Material. The variation of the volume and parameters as a function of the applied pressure are shown in Fig. 6, Similarly, the computed unit cell volumes and lattice parameters of this material for eighteen different external isotropic pressures are given in Table S.3 of the Supplementary Material and displayed in Fig. 7. For anhydrous cadmium oxalate, the calculated volumes and lattice parameters under the effect of eighteen pressures directed along the direction of minimum compressibility, $U_{\text {min }}^{C}=(-0.31,0.00,0.95)$, are reported in Table S.4 of the Supplementary Material and plotted in Fig. 8. The volume and parameters for this material submitted to twelve different isotropic pressures are provided in Table S.5 and displayed in Fig. 9. Finally, for lead oxalate dihydrate, the unit cell volumes and parameters under sixteen different pressures applied in the direction of minimum Poisson's ratio, $U_{\min }^{L}=(0.66,-0.71$, 0.25 ), are given in Table S.6 and plotted in Fig. 10. The corresponding results for this material submitted to twenty isotropic pressures are given in Table S.7 and shown in Fig. 11.

\section{Discussion}

\section{Crystal structures}

As may be observed in Table 1, the results obtained for the lattice parameters of the considered materials are in good agreement with experiment, the differences in the computed unit cell volumes and densities being of the order of $0.2,2.0$ and $3.3 \%$ for $\mathrm{ZnC}_{2} \mathrm{O}_{4}, \quad \mathrm{CdC}_{2} \mathrm{O}_{4}$ and $\mathrm{PbC}_{2} \mathrm{O}_{4} \cdot 2 \mathrm{H}_{2} \mathrm{O}$, respectively. The excellent agreement in the calculated $\mathrm{X}$ ray powder patterns of these materials (Fig. 1) provides additional support to the theoretical treatment employed for these materials.

The structure of the unit cell of $\mathrm{ZnC}_{2} \mathrm{O}_{4}$, shown in Fig. 2(a), is composed of chains formed with alternate oxalate $\mathrm{C}_{2} \mathrm{O}_{4}$ and $\mathrm{ZnO}_{4}$ planar groups. The chains are held together by means of weak van der Waals forces only. Similarly, as shown in Fig. 2(b), the structure of $\mathrm{CdC}_{2} \mathrm{O}_{4}$ is based in chains composed of alternate oxalate fragments and $\mathrm{CdO}_{6}$ polyhedra. However, the different chains in cadmium oxalate are bonded through $\mathrm{Cd}-\mathrm{O}$ bonds. Finally, as shown in Fig. 2(c), the structure of lead oxalate dihydrate is formed with folded zig-zag chains of alternate oxalate and $\mathrm{PbO}_{7}$ polyhedra. The lead atom in this material is coordinated with six oxygen atoms belonging to four different oxalate fragments and one oxygen atom from a water molecule. Therefore, this water molecule is structural, the other one being held to the structure by means of hydrogen bonds only (free water). 
Table 5. Minimum and maximum Poisson's ratios for $\mathrm{ZnC}_{2} \mathrm{O}_{4}, \mathrm{CdC}_{2} \mathrm{O}_{4}$ and $\mathrm{PbC}_{2} \mathrm{O}_{4} \cdot 2 \mathrm{H}_{2} \mathrm{O}$. The directions for the associated longitudinal and transverse directions are also given.

\begin{tabular}{cccccc}
\hline $\boldsymbol{v}_{\min }$ & $\boldsymbol{U}_{\min }^{L}$ & $\boldsymbol{U}_{\min }^{\boldsymbol{T}}$ & $\boldsymbol{v}_{\max }$ & $\boldsymbol{U}_{\max }^{L}$ & $\boldsymbol{U}_{\max }^{\boldsymbol{T}}$ \\
\hline \multicolumn{5}{c}{ Zinc oxalate } \\
\hline-0.29 & $(0.72,-0.69,0.00)$ & $(0.69,0.72,0.00)$ & 0.62 & $(0.40,0.26,-0.88)$ & $(-0.65,0.60,-0.47)$ \\
\hline \multicolumn{5}{c}{ Cadmium oxalate } \\
\hline-0.26 & $(-0.70,-0.71,0.06)$ & $(0.70,-0.69,0.09)$ & 0.79 & $(-0.38,0.30,0.87)$ & $(0.62,-0.62,0.48)$ \\
\hline \multicolumn{5}{c}{ Lead oxalate dihydrate } \\
\hline-0.07 & $(0.66,-0.71,-0.25)$ & $(0.62,-0 . .70,-0.36)$ & 0.67 & $(1.00,0.00,0.00)$ & $(0.00,1.00,0.00)$ \\
\hline
\end{tabular}
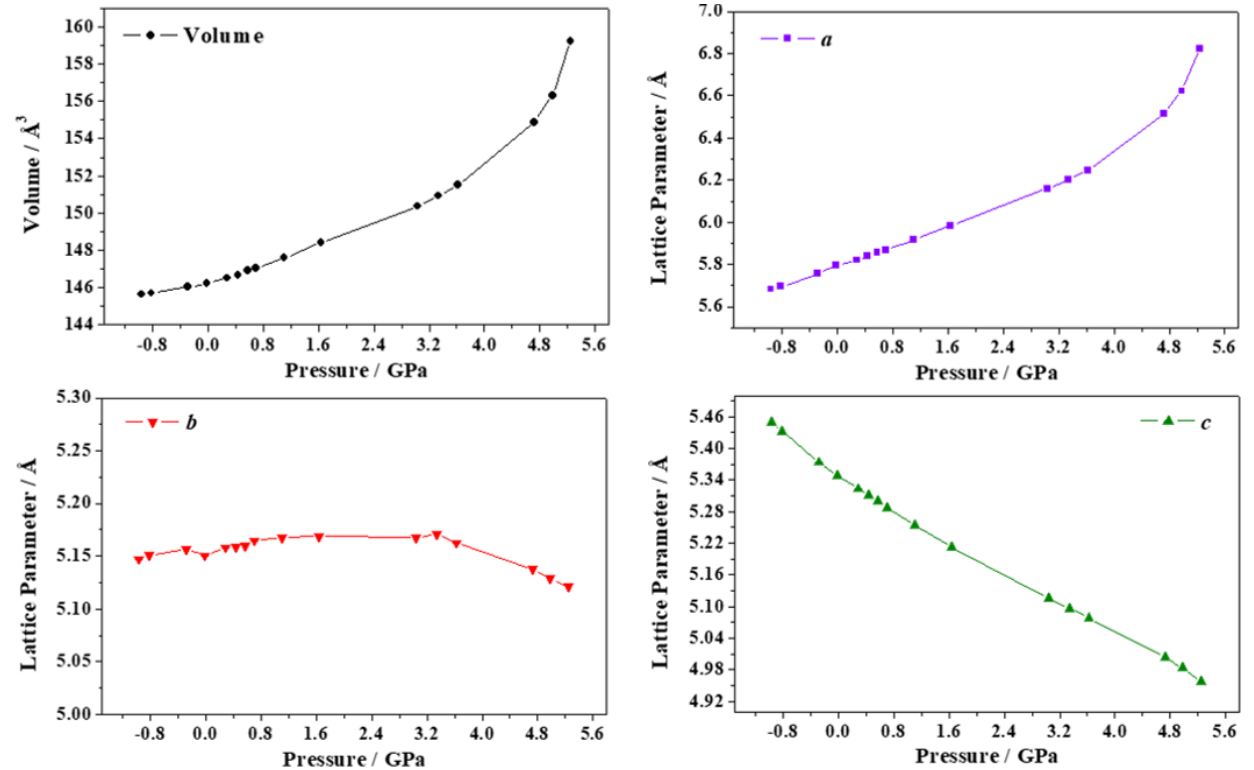

Fig. 6. Calculated unit cell volumes and lattice parameters of $\mathrm{ZnC}_{2} \mathrm{O}_{4}$ as a function of the applied external pressure directed along the minimum compressibility direction, $U_{\min }^{C}=(-0.16,0.0,0.99)$.

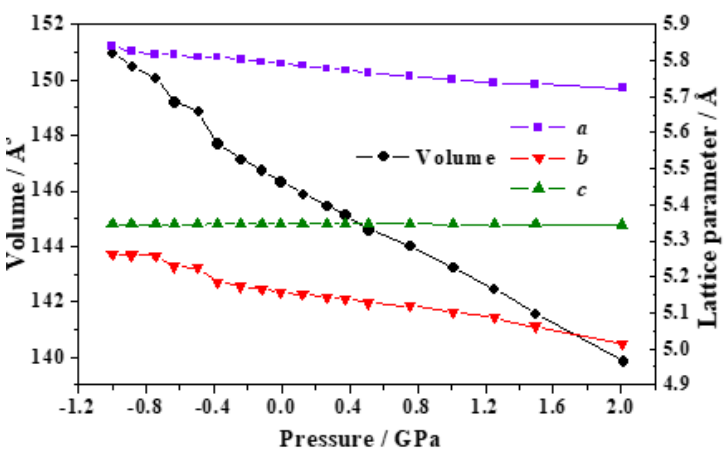

Fig. 7. Calculated unit cell volumes and lattice parameters of zinc oxalate as a function of the applied isotropic pressures.

\section{Mechanical stability}

The fulfilment of the Born mechanical stability conditions [107-108] was analyzed from the calculated stiffness matrices reported in Table 2 . The necessary and sufficient condition for mechanical stability is that all eigenvalues of the $C$ matrix be positive [108]. The $C$ matrices were diagonalized numerically and all eigenvalues were found to be positive. Hence, it follows that the crystalline structures of the zinc and cadmium oxalates and lead oxalate dihydrate are mechanically stable.

\section{Elastic properties}

The calculated ductility indices (Table 3 ) for the materials studied were $D=1.37,1.90$ and 2.16 , respectively.
Consequently, while zinc oxalate is a brittle material, the cadmium and lead oxalates are ductile [109-110]. The calculated Vickers hardness for the materials considered, $H=$ $6.35,2.25$ and 0.20 , respectively. Thus, zinc oxalate is a material of intermediate hardness and the cadmium and lead oxalate materials have low and very low harnesses $[111,106]$. The values of the universal anisotropy index [112-113] are $A^{U}=3.63,4.63$ and 2.41, respectively, and, therefore, the considered materials have a significant elastic anisotropy. The large elastic anisotropy results from the very different values of the stiffness tensor elements, $C_{i i}(i=1,2,3)$, along the different directions (see Table 2). 

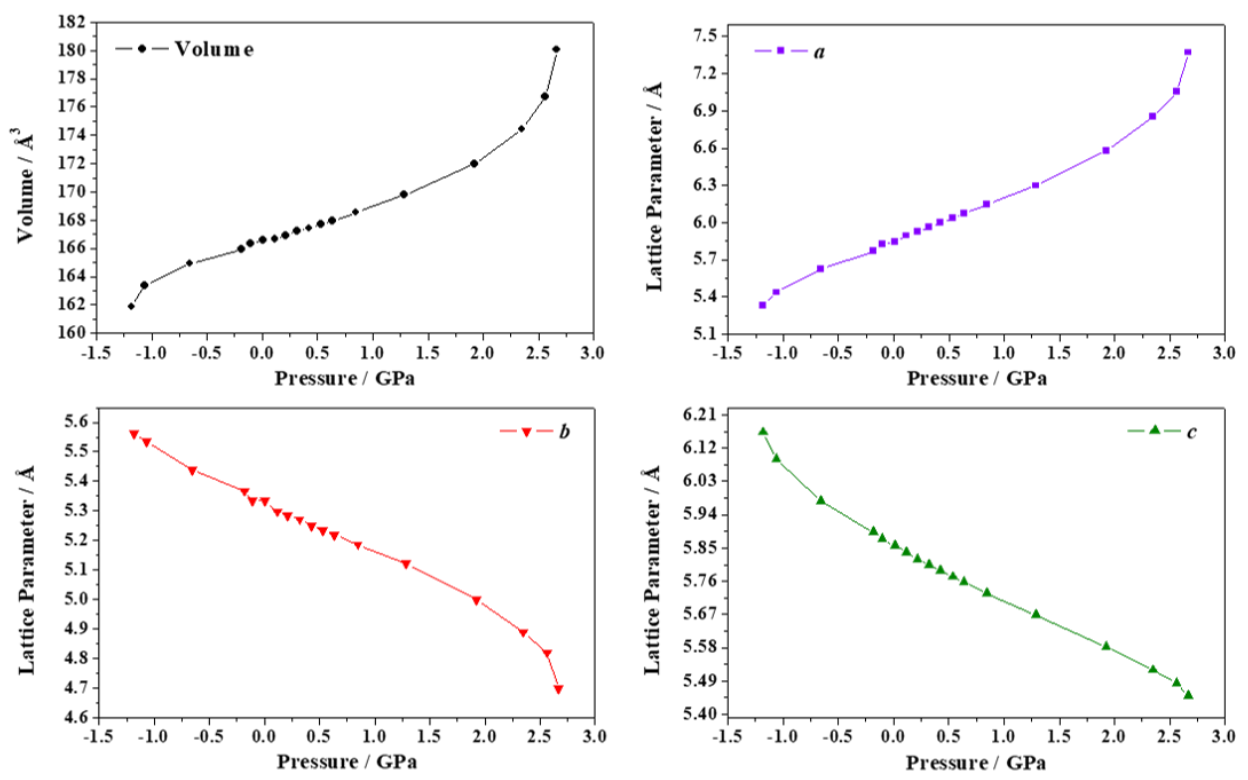

Fig. 8. Calculated unit cell volumes and lattice parameters of $\mathrm{CdC}_{2} \mathrm{O}_{4}$ as a function of the applied external pressure directed along the minimum compressibility direction, $U_{\text {min }}^{C}=(-0.31,0.00,0.95)$.

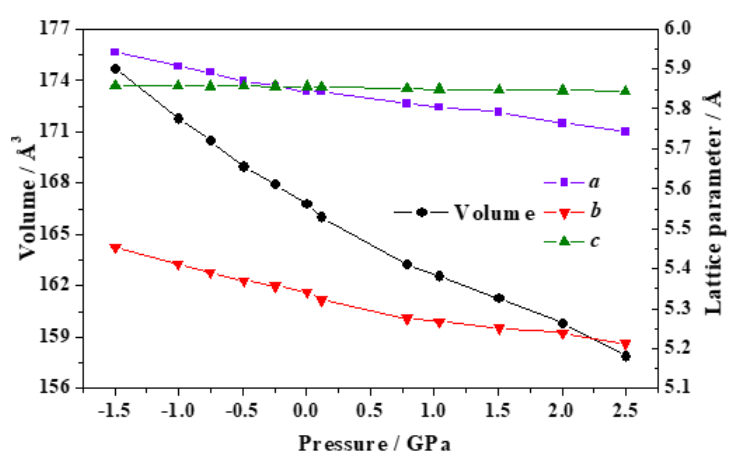

Fig. 9. Calculated unit cell volumes and lattice parameters of cadmium oxalate as a function of the applied isotropic pressures

\section{Negative Poisson's ratios}

The Poisson's ratio [14] is defined, for a stress applied to a solid material along a certain direction, as the negative value of the ratio of the subsequent differential transverse and longitudinal strains, $v=-\delta \epsilon_{\text {trans }} / \delta \epsilon_{\text {long }}$. In this definition, the strain $\epsilon_{i}$ is the variation of the solid size along the direction $i$ divided by the initial size, $\epsilon_{i}=\Delta L_{i} / L_{I}$. In the majority of cases, $v$ is positive because if a positive pressure is applied along a certain direction, a contraction of the solid along the longitudinal direction and an expansion along all the transverse directions is expected. Nevertheless, in some cases a solid material may behave in a counterintuitive way and anomalous negative Poisson's ratios (NPR) [9-14] can be found for certain longitudinal and transverse directions. NPR materials laterally expand when they are stretched or laterally shrink when compressed.

Due to the well-known relationship between the value of the elastic anisotropy index and the minimal and maximal values of the Poisson's ratio $[92,114]$, there were cogent reasons to study the possible anomalous elastic behavior of the considered materials. Thus, the dependence of the elastic properties of these materials with the direction of the applied strain was obtained and analyzed in detail. As may be seen in Table 5 and Fig. 3, Fig. 4 and Fig. 5, the three materials show negative values of the minimum Poisson's ratio, The precise values are $-0.29,-0.26$ and -0.06 , respectively. 


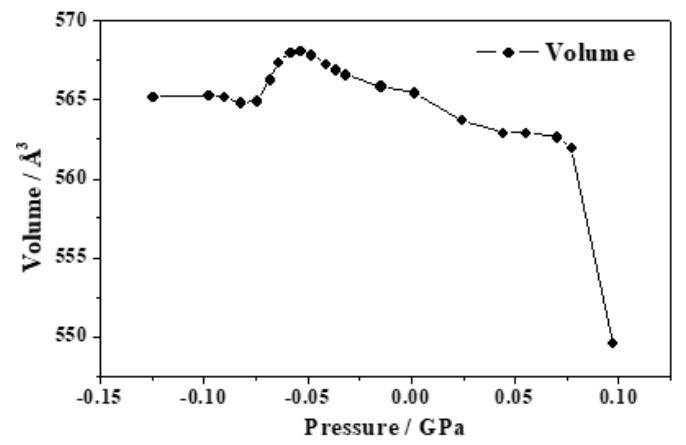

Fig. 10. Calculated unit cell volume of lead oxalate dihydrate as a function of the applied external pressure directed along the minimum Poison Ratio direction, $U_{\min }^{L}=(0.66,-0.71,-0.25)$.
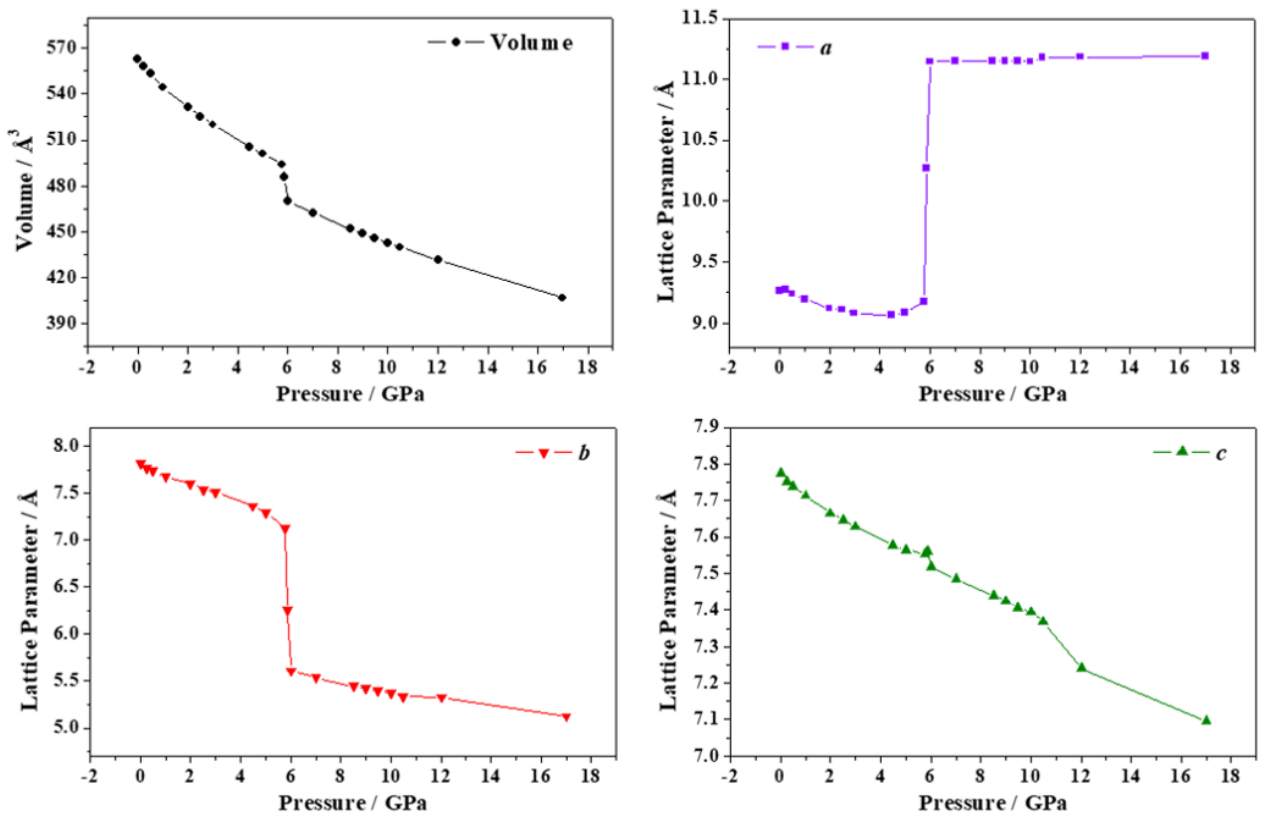

Fig. 11. Calculated unit cell volumes and lattice parameters of lead oxalate dihydrate as a function of the applied isotropic pressures.

\section{Negative linear compressibility}

The occurrence of negative values of the Poisson's ratio in a given material is often accompanied by the presence of negative linear compressibility phenomenon [1-2, 6-7]. The overall compressibility (the inverse of bulk modulus) measures the relative change of the volume of a material as a response to a pressure variation. It must be positive for space unconstrained solid materials which are thermodynamically and mechanically stable and are submitted to isotropic pressures [14, 115-116]. Hence, a material submitted to a hydrostatic (isotropic) pressure cannot increase its volume, unless it is unstable. The negative linear compressibility (NLC) phenomenon is not related to unstable materials. There are two types of NLC [1-7, 20]: (a) Anisotropic linear compressibility (ANLC): Increase of the volume of a material when is submitted to a uniform compression directed along a given direction. In this case the directional derivative of the volume with respect to pressure is negative, i.e., $k^{V}=$ $-1 / V \cdot\left(\partial V / \partial P_{i}\right)_{p}$, where $V$ stands for the unit cell volume and $P_{i}$ is an external pressure applied along a certain direction $u_{i}$; (b) Isotropic linear compressibility (INLC): Increase of one or two single dimensions of the unit cell of a material under the application of an isotropic pressure. Now, $k^{i}=$ $-1 / a_{i} \cdot\left(\partial a_{i} / \partial P\right)_{p}$, where $a_{i}$ is a certain parameter of the unit cell, is negative. In this case, the volume does not increase and the positive variation of the parameters in some directions is compensated by a larger negative variation of the parameters in the remaining directions.

The response of a solid material can be completely different when is submitted to isotropic and anisotropic pressures. For example, in previous works, the four possible cases have been observed: $i$ ) Materials exhibiting INLC and ANLC, as the croconic acid, oxalic acid dihydrate and uranyl squarate monohydrate $[1-4,6] ; i i)$ Materials exhibiting INLC only, as the silver oxalate [7]; iii) Materials displaying ANLC only, as the anhydrous oxalic acid [2]; iv) Normal materials which do not show these effects. The ANLC and INLC phenomena in the materials considered are studied in the next Sections. 
Table 6. Calculated compressibilities $\left(k_{V}=-1 / V \cdot(\partial V / \partial P)_{P}\right)$ of zinc oxalate for applied external pressures directed along $U_{\text {min }}^{C}$ direction between $-0.40 \mathrm{GPa}$ and $-5.20 \mathrm{GPa}$.

\begin{tabular}{cccccc}
\hline $\mathbf{P}(\mathbf{G P a})$ & $\boldsymbol{k}_{\boldsymbol{V}}\left(\mathbf{T P a}{ }^{\mathbf{- 1}}\right)$ & $\mathbf{P}(\mathbf{G P a})$ & $\boldsymbol{k}_{\boldsymbol{V}}\left(\mathbf{T P a}{ }^{-\mathbf{1}}\right)$ & $\mathbf{P}(\mathbf{G P a})$ & $\boldsymbol{k}_{\boldsymbol{V}}\left(\mathbf{T P a}^{-\mathbf{1}}\right)$ \\
\hline-0.40 & -5.22 & 1.60 & -10.07 & 3.60 & -11.03 \\
-0.20 & -6.23 & 1.80 & -10.32 & 3.80 & -12.44 \\
0.00 & -6.93 & 2.00 & -10.48 & 4.00 & -14.80 \\
0.20 & -7.44 & 2.20 & -10.53 & 4.20 & -18.45 \\
0.40 & -7.87 & 2.40 & -10.48 & 4.40 & -23.74 \\
0.60 & -8.25 & 2.60 & -10.35 & 4.60 & -31.11 \\
0.80 & -8.63 & 2.80 & -10.18 & 4.80 & -40.99 \\
1.00 & -9.01 & 3.00 & -10.04 & 5.00 & -53.85 \\
1.20 & -9.40 & 3.20 & -10.03 & 5.20 & -70.14 \\
1.40 & -9.76 & 3.40 & -10.30 & - & - \\
\hline
\end{tabular}

Table 7. Calculated compressibilities $\left(k_{V}=-1 / V \cdot(\partial V / \partial P)_{P}\right)$ of cadmium oxalate for applied external pressures directed along $U_{\text {min }}^{C}$ direction between $-0.40 \mathrm{GPa}$ and $-2.50 \mathrm{GPa}$.

\begin{tabular}{cccccc}
\hline $\mathbf{P}(\mathbf{G P a})$ & $\boldsymbol{k}_{\boldsymbol{V}}\left(\mathbf{T P a}^{\mathbf{- 1}}\right)$ & $\mathbf{P}(\mathbf{G P a})$ & $\boldsymbol{k}_{\boldsymbol{V}}\left(\mathbf{T P a}^{-\mathbf{1}}\right)$ & $\mathbf{P}(\mathbf{G P a})$ & $\boldsymbol{k}_{\boldsymbol{V}}\left(\mathbf{T P a}^{-\mathbf{1}}\right)$ \\
\hline-0.40 & -14.27 & 0.60 & -15.57 & 1.60 & -18.24 \\
-0.30 & -13.51 & 0.70 & -15.99 & 1.70 & -19.33 \\
-0.20 & -13.07 & 0.80 & -16.32 & 1.80 & -21.00 \\
-0.10 & -12.91 & 0.90 & -16.57 & 1.90 & -23.42 \\
0.00 & -12.98 & 1.00 & -16.73 & 2.00 & -26.82 \\
0.10 & -13.23 & 1.10 & -16.83 & 2.10 & -31.40 \\
0.20 & -13.61 & 1.20 & -16.91 & 2.20 & -37.43 \\
0.30 & -14.08 & 1.30 & -17.01 & 2.30 & -45.17 \\
0.40 & -14.59 & 1.40 & -17.20 & 2.40 & -54.92 \\
0.50 & -15.10 & 1.50 & -17.57 & 2.50 & -66.97 \\
\hline
\end{tabular}

Table 8. Calculated compressibilities $\left(k_{V}=-1 / V \cdot(\partial V / \partial P)_{P}\right)$ of lead oxalate dihydrate oxalate for applied external pressures directed along $U_{\text {min }}^{L}$ direction between $-0.081 \mathrm{GPa}$ and $-0.055 \mathrm{GPa}$.

\begin{tabular}{cccc}
\hline $\mathbf{P}(\mathbf{G P a})$ & $\boldsymbol{k}_{\boldsymbol{V}}\left(\mathbf{T P a} \mathbf{a}^{\mathbf{1}}\right)$ & $\mathbf{P}(\mathbf{G P a})$ & $\boldsymbol{k}_{\boldsymbol{V}}\left(\mathbf{T P a} \mathbf{a}^{\mathbf{1}}\right)$ \\
\hline-0.081 & 35.877 & -0.069 & -423.099 \\
-0.079 & -4.777 & -0.067 & -363.484 \\
-0.077 & -61.065 & -0.065 & -297.220 \\
-0.075 & -134.627 & -0.063 & -228.465 \\
-0.073 & -227.082 & -0.061 & -160.613 \\
-0.072 & -280.891 & -0.059 & -96.353 \\
-0.071 & -340.014 & -0.057 & -37.737 \\
-0.070 & -404.641 & -0.055 & 13.764 \\
\hline
\end{tabular}

\section{NLC in anhydrous zinc oxalate.}

The variation of the optimized unit cell volume and lattice parameters of zinc oxalate as a function of the external pressures applied along the direction of minimum compressibility (nearly the of $c$ axis in this case) are displayed in Fig. 6. The unit cell volume increases upon anisotropic compression for pressures ranging from -0.96 to $5.24 \mathrm{GPa}$. Hence, $\mathrm{ZnC}_{2} \mathrm{O}_{4}$ exhibits $\mathrm{ANLC}$ in this range. Additional theoretical calculations revealed that the compressibility becomes positive in the negative pressure side at $-1.25 \mathrm{GPa}$.

The computed compressibilities of zinc oxalate are shown in Fig. 12 and the corresponding values from -0.40 to 5.20 $\mathrm{GPa}$ are reported in Table 6 . The magnitude of negative compressibility increases rapidly for a large portion of the pressure range beginning at $3.6 \mathrm{GPa}$. At $\mathrm{P}=3.60 \mathrm{GPa}$, the compressibility is $k_{V}=-11.0 \mathrm{TPa}^{-1}$ and at $\mathrm{P}=5.20 \mathrm{GPa}$ is $k_{V}=-70.1 \mathrm{TPa}^{-1}$. The volume expansion is so large that the material becomes unstable for pressures near 5.50 GPa.

The calculated unit cell volumes and lattice parameters of zinc oxalate as a function of different applied isotropic pressures are plotted in Fig. 7. Under isotropic pressures, zinc oxalate presents an irregular behavior of the lattice parameters for pressures between $-1.0 \mathrm{GPa}$ and $0.5 \mathrm{GPa}$, and the $c$ lattice parameter oscillates slightly in this range. Zinc oxalate displays INLC intermittently in this range. However, the magnitude of the INLC in zinc oxalate seems to be very small and, in comparison with the ANLC, is not significant since as was shown in the previous Section, this material displays a large ANLC effect for a wide range of applied external pressures directed along the minimum compressibility direction.

The mechanical behavior of zinc oxalate under isotropic pressures is completely different to that for anhydrous silver oxalate since it was shown in a previous work [7] that the later material presents the more extreme INLC effect found up to date.

\section{$N L C$ in anhydrous cadmium oxalate}

As can be observed in Fig. 8, the unit cell volume of cadmium oxalate increases upon anisotropic compression for pressures ranging from -1.18 to $2.67 \mathrm{GPa}$ and, consequently, exhibits ANLC in this range. The compressibility becomes positive in the negative pressure side at $-1.20 \mathrm{GPa}$. The computed compressibilities are displayed in Fig. 13 and given in Table 7. The magnitude of negative compressibility increases rapidly from $1.8 \mathrm{GPa}$. At $\mathrm{P}=1.80 \mathrm{GPa}$, the compressibility is $k_{V}=-21.0 \mathrm{TPa}^{-1}$ and at $\mathrm{P}=2.50 \mathrm{GPa}$ is $k_{V}=-67.0 \mathrm{TPa}^{-1}$. 
As it occurred for zinc oxalate, the volume expansion becomes so drastic that the material becomes unstable when the external pressures are larger than about $2.70 \mathrm{GPa}$.

The calculated unit cell volumes and lattice parameters of cadmium oxalate as a function of different applied isotropic pressures are plotted in Fig. 9. Under isotropic pressures, cadmium oxalate does not show any sign of isotropic negative linear compressibility.

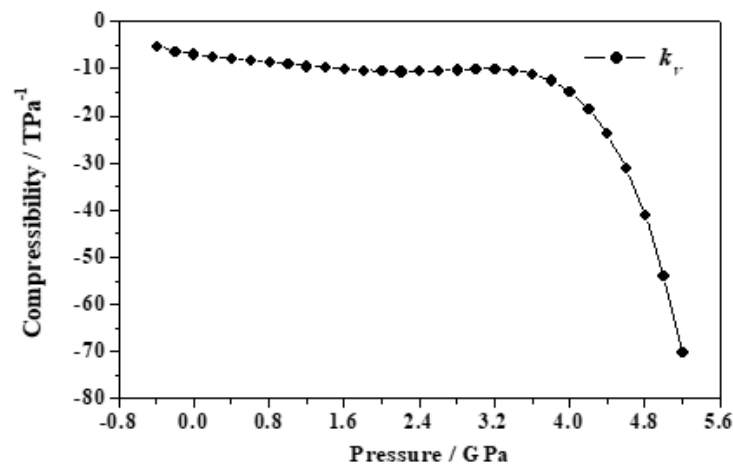

Fig. 12. Calculated compressibilities $\left(k_{V}=-1 / V \cdot(\partial V / \partial P)_{P}\right)$ of zinc oxalate as a function of the applied external pressure directed along the minimum compressibility direction in the pressure range from $-0.4 \mathrm{GPa}$ to $5.2 \mathrm{GPa}$.

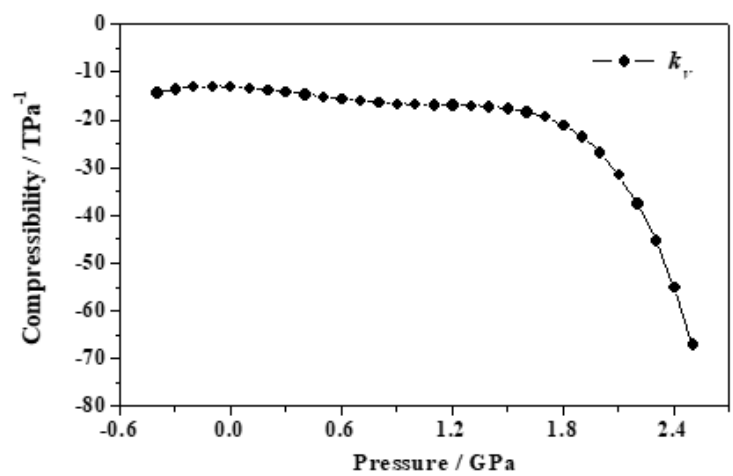

Fig. 13. Calculated compressibilities $\left(k_{V}=-1 / V \cdot(\partial V / \partial P)_{P}\right)$ of cadmium oxalate as a function of the applied external pressure directed along the minimum compressibility direction in the pressure range from $-0.4 \mathrm{GPa}$ to $2.5 \mathrm{GPa}$.

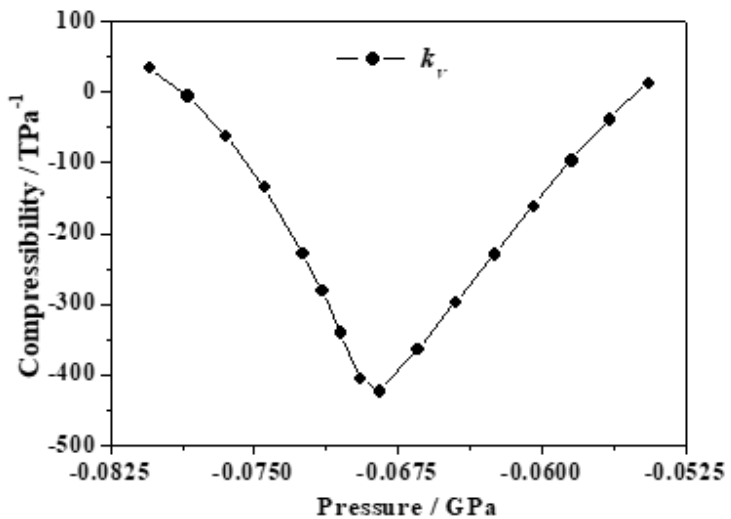

Fig. 14. Calculated compressibilities $\left(k_{V}=-1 / V \cdot(\partial V / \partial P)_{P}\right)$ of lead oxalate dihydrate as a function of the applied external pressure directed along the minimum Poisson ratio direction in the pressure range from $-0.08 \mathrm{GPa}$ to $-0.05 \mathrm{GPa}$.

\section{NLC in lead oxalate dihydrate}

As may be noticed in Fig. 10, this material exhibits ANLC for a small pressure range, from -0.055 and $-0.078 \mathrm{GPa}$. The computed compressibilities are shown in Fig. 14 and given in Table 8 . The magnitude of the negative compressibility varies rapidly in this pressure range and attains a maximum at $\mathrm{P}=-0.069 \mathrm{GPa}$, where if becomes $k_{V}=-423.1 \mathrm{TPa}^{-1}$. While the magnitude of the NLC is much larger than for the zinc and cadmium oxalates, the pressure range is much narrower. Although the NLC magnitude is very large, is nearly the half of the value found recently for silver oxalate [7] when this material is submitted to isotropic pressures, -831.9 $\mathrm{TPa}^{-1}$. The magnitude of the ANLC in silver oxalate is the largest found up to date, the ANLC pressure range (from -0.51 to $13.4 \mathrm{GPa}$ ) being extremely wide [7].

As shown in Fig. 10, the crystal structure of lead oxalate dihydrate has a very large volume decrease for anisotropic positive pressures directed along the direction of the minimum Poisson ratio larger than $+0.08 \mathrm{GPa}$. This is due to the fact that this material undergoes a pressure induced phase transition. The lattice parameters and atomic positions of the new phase under a pressure value of $0.092 \mathrm{GPa}$ directed along the direction of the minimum Poisson ratio are provided as Supplementary Material in a file of CIF (Crystallographic Information File) type.

Lead oxalate dihydrate also undergoes a phase transition when is submitted to isotropic pressures near $5.85 \mathrm{GPa}$, as observed very clearly in Fig. 11. The lattice parameters and atomic positions of this pressure induced phase at $6.0 \mathrm{GPa}$ are also reported as Supplementary Material in a file with CIF format.

\section{Crystal structure deformation under anisotropic} pressures

To assess the crystal structure variations at the basis of the INLC phenomena in the anhydrous zinc and cadmium oxalates and lead oxalate dihydrate, the optimized structures under pressure were analyzed in detail.

\section{Deformation of the crystal structure of $\mathrm{ZnC}_{2} \mathrm{O}_{4}$}

The main structural variations associated to the volume change in zinc oxalate under the effect of anisotropic pressures can be seen in Table S. 8 of the Supplementary Material. In this table, the structural changes between the structures optimized at the pressures $-0.286,0.0$, and $0.283 \mathrm{GPa}$ are provided. The lattice parameter $b$ is very similar at the three pressures. The application of positive pressures along $U_{\min }^{C}$ does no change significantly the oxalate fragment geometry but leads to a large decrease of the $\mathrm{Zn}-01$ distance which is nearly the half of the decrease of the $c$ lattice parameter, that is, the distance between two $\mathrm{ZnO}_{4}$ groups in the same chain $\left(\mathrm{Zn}-\mathrm{Zn}^{* *}\right.$ distance, see Fig. 2). The $\mathrm{ZnO}_{4}$ groups become shorter along $c$ direction and longer along the perpendicular direction. The $02-\mathrm{Zn}-01$ angle increases. The decrease in $c$ lattice parameter is accompanied by the increase of the interchain distance $\mathrm{Zn}-\mathrm{Zn}^{* * *}$ (along $a$ axis). The interchain distance 
$\mathrm{Zn}-\mathrm{Zn}^{*}$ (along $b$ axis) remains nearly constant. Since the increase of the interchain distance is larger than the decrease of the intrachain distances the total volume increases leading to the ANLC in zinc oxalate.

\section{Deformation of the crystal structure of $\mathrm{CdC}_{2} \mathrm{O}_{4}$}

As shown in Table S.9 of the Supplementary Material, the application of pressures along $U_{\text {min }}^{C}$ does no change significantly the geometry of the oxalate fragments but leads to a large decrease of the $\mathrm{Cd}-\mathrm{O}$ distances which is the main responsible of the decrease of the $c$ lattice parameter. The lattice parameter $c$ is identical to the distance between two $\mathrm{CdO}_{6}$ groups in the same chain $\left(\mathrm{Cd}-\mathrm{Cd}^{*}\right.$ distance, see Fig. 2). This decrease is accompanied by the increase of the interchain distance $\left(\mathrm{Cd}-\mathrm{Cd}^{@}\right)$. Since the increase of the interchain distance (see $a$ lattice parameter) is larger than the decrease of the intrachain distance, the total volume increases leading to the ANLC in cadmium oxalate. The mechanism is similar to that found in zinc oxalate, but in this case the chains do not interact by means of weak van der Waals forces since they are bonded through $\mathrm{Cd}-\mathrm{O}$ bonds (see Fig. 2(b)). The larger rigidity of the interaction between the chains leads to the emergence of the instability in the structure at a much smaller applied external pressure in cadmium oxalate.

\section{Deformation of the crystal structure of $\mathrm{PbC}_{2} \mathrm{O}_{4} \cdot 2 \mathrm{H}_{2} \mathrm{O}$}

As may be seen in Table S.10 of the Supplementary Material, the application of increasingly large negative (expansive) pressures along $U_{\min }^{L}$ within the range -0.055 and $-0.078 \mathrm{GPa}$ leads to a large decrease of the $\mathrm{Pb}-\mathrm{Pb}^{\#}$ distances within a given folded chain (see Fig, 2(c)). At the same time, the interchain distance along $a$ direction (the $\mathrm{Pb}-\mathrm{Pb}^{*}$ distance in Table S.10) increases and the interchain distance along $b$ direction decreases (see $\mathrm{Pb}-\mathrm{Pb}^{* *}$ distance). The distances along $c$ direction remain almost constant. Since the decrease of the interchain distances along $b$ direction is much larger than the increase of the distance along $a$ direction, the total unit cell volume decreases and, consequently, this material shows ANLC.

\section{Conclusions}

The anhydrous zinc and cadmium oxalates and lead oxalate dihydrate were studied using first-principles solid-state methods based in Density Functional Theory employing plane waves and pseudopotentials. The computed crystal structures and X-ray powder diffraction patterns were in very good agreement with their experimental counterparts. The elastic properties of these materials were also determined. Since these properties have not been measured experimentally, they were predicted. A large set of relevant elastic data, including the bulk, Young and shear moduli, the Poisson's ratio, ductility, hardness and anisotropy indices and the bulk modulus pressure derivatives were reported. The materials considered were found to be very anisotropic and to display the important NPR and NLC phenomena.
The elastic behavior of the anhydrous zinc and cadmium oxalates was found to be analogous suggesting a common mechanical performance of the group of anhydrous divalent metal oxalate materials having structures based in chains formed by alternate oxalate and metal oxygen polyhedra. In these systems, the ANLC effect appears to be due to the fact that when an anisotropic compression is made along a direction near to the direction of the chains, although the intrachain distances decrease significantly, the interchain distances along the perpendicular directions increase to a larger extent resulting in a net increase of the unit cell volume. These structural variations are similar to the NLC mechanisms encountered in previous works [1-2] for the croconic and oxalic acids. These materials are formed from structural elements as sheets or chains linked through weak van der Waals interactions. In these materials, the weak bonding between the sheets or chains also accommodates the structural variations arising from the application of pressure but the resulting deformations are anomalous and negative values of the compressibility are obtained due to the large increase of the intersheet or interchain distances. For uranyl squarate monohydrate [6] and silver oxalate [7], the crystal structures are three-dimensional and are not based on chains or sheets. The NLC effect in uranyl squarate monohydrate [6] is related to the changes of the internal geometry of uranyl coordination polyhedra under pressure and for silver oxalate to the variations of the relative distances of the silver coordination polyhedra [7]. These mechanisms are different from the majority of mechanisms used up to date to rationalize the NLC phenomenon as the ferroelastic instabilities, phonon instabilities, reverse ferroelastic phase transitions, correlated polyhedral tilts and helical and wine-rack structural motifs [20]

Since the state of the art of the theoretical solid state methodology is very advanced, high-quality applications performed in large scale computer installations with the appropriate methods and calculation parameters have predictive value and generally lead to material properties in good agreement with experiment [117-142]. The present computational study was carried out using very demanding calculation parameters chosen to obtain nearly converged crystal structures, energies and elastic properties with respect to these parameters and therefore must be properly reproducible. Similar computations based on accurate enough computational methods and carried out with a sufficient level of complexity associated to the calculation parameters employed should lead to essentially the same conclusions. The results of this paper should be confirmed experimentally. Due to the large availability of the materials studied and the fact that high pressure methods are well stablished, the verification must be a relatively easy mater from the experimental point of view.

The present work and the previous studies [1-7] suggest that many other organic and metal-organic materials could exhibit extremely anomalous negative mechanical phenomena. The possibility of discovering even larger NLC effects in these materials is very significant Since oxalic acid [2-3] and silver oxalate [7] were previously shown to exhibit 
a highly anomalous behavior, these works and the present study suggest that the mechanical properties of additional members of the group of metal oxalates should be studied in detail.

Acknowledgements Supercomputer time by the CTI-CSIC center is greatly acknowledged. One of the authors (VT) was supported by the Ministry of Science, Innovation and Universities within the Project FIS2016-77726-C3-1-P.

Compliance with Ethical Standards: This study was funded by the Ministry of Science, Innovation and Universities (grant number FIS2016-77726-C3-1-P).

Conflict of Interest: The authors declare that they have no conflict of interest.

\section{References}

1. Colmenero F (2019) Anomalous mechanical behavior of the deltic, squaric and croconic cyclic oxocarbon acids. Mater Res Express 6, 045610.

2. Colmenero F (2019) Mechanical Properties of Anhydrous Oxalic Acid and Oxalic Acid Dihydrate. Phys Chem Chem Phys 21, 26732690.

3. Colmenero F (2019) Negative Area compressibility in oxalic acid dihydrate. Mater Lett 245, 25-28.

4. Colmenero F (2019) Addendum: Anomalous mechanical behavior of the deltic, squaric and croconic cyclic oxocarbon acids. Mater Res Express 6, 069401.

5. Colmenero F (2018) Revealing Rutherfordine Mineral as an Auxetic Material. Appl Sci 8, 2281-2290.

6. Colmenero F, Cobos J, Timón V (2019) Negative Linear Compressibility in Uranyl Squarate Monohydrate. J Phys: Condens Matter 31, 175701

7. Colmenero F (2019) Silver Oxalate: Mechanical Properties and Extreme Negative Mechanical Phenomena. Adv. Theor. Simul. 2, 1900040.

8. Payne MC, Teter MP, Ailan DC, Arias A, Joannopoulos JD (1992) Iterative minimization techniques for ab initio total-energy calculations: molecular dynamics and conjugate gradients. Rev Mod Phys 64, 1045-1097.

9. Lakes RS (1987) Foam structures with a negative Poisson's ratio. Science 235, 1038-1040.

10. Wojciechowski KW (1987) Constant thermodynamic tension Monte Carlo studies of elastic properties of a two-dimensional system of hard cyclic hexamers. Mol Phys 61, 1247-1258.

11. Lakes RS (1993) Advances in negative Poisson's ratio materials. Adv Mater 5, 293-296.

12. Grima JN, Jackson R, Alderson A, Evans KE (2000) Do zeolites have negative Poisson's ratios? Adv Mater 12, 1912-1918.

13. Greaves GN, Greer AL, Lakes RS, Rouxel T (2011) Poisson's ratio and modern materials. Nat Mater 10, 823-837.

14. Lakes RS (2017) Negative-Poisson's-ratio materials: auxetic solids. Annu Rev Mater Res 47, 63-81.

15. Baughman RH, Stafström S, Cui C, Dantas SO (1998) Materials with Negative Compressibilities in One or More Dimensions. Science 279, 1522-1524.

16. Kornblatt JA, Sirota EB, King HE, Baughman RH, Cui C (1998) Materials with Negative Compressibilities. Science 281, 143-143.

17. Evans KE, Alderson A (2000) Auxetic Materials: Functional Materials and Structures from Lateral Thinking! Adv Mater 12, 617-628.
18. Spinks GM, Wallace GG, Fifield LS, Dalton LR, Mazzoldi A, De Rossi D, Khayrullin I. Baughman RH (2002) Pneumatic Carbon Nanotube Actuators. Adv Mater 14, 1728-1732.

19. Weng CN, Wang KT, Chen, T. (2008) Design of Microstructures and Structures with Negative Linear Compressibility in Certain Directions. Adv Mater Res 33-37, 807-814.

20. Cairns AB, Goodwin L (2015) Negative Linear Compressibility. Phys Chem Chem Phys 17, 20449-20465.

21. Evans KE (1991) Auxetic polymers: a new range of materials Endeavour 15, 170-174.

22. Branka AC, Heyes DM, Wojciechowski KW (2011) Auxeticity of cubic materials under pressure. Phys Stat Sol (b) 248, 96-104.

23. Baran EJ (2014) Review: Natural oxalates and their analogous synthetic complexes. J Coord Chem 67, 3734-3768.

24. Wark M, Kessle H, Schulz-Ekloff, G (1997) Growth and reactivity of zinc and cadmium oxide nano-particles in zeolites. Microporous Mater 8, 241-253.

25. Zhang S, Tang Y, Vlahovic B (2016) A Review on preparation and applications of silver-containing nanofibers. Nanoscale Res Lett 11, 80-87.

26. Ahmad T, Ganguly A, Ahmed J, Ganguli AK, Abdullah O, Alhartomy A (2011) Nanorods of transition metal oxalates: A versatile route to the oxide nanoparticles. Arab J Chem 4, 125-134.

27. Sengupta B, Tamboli CA, Sengupta R (2011) Synthesis of nicke oxalate particles in the confined internal droplets of W/O emulsions and in systems without space confinement. Chem Eng J 169, 379 389.

28. Zhou XL, Yan ZG, Han XD (2014) From ascorbic acid to oxalate: Hydrothermal synthesis of copper oxalate microspheres and conversion to oxide. Mater Lett 118, 39-42.

29. Sarada K, Vijisha KR, Muraleedharan K (2016) Exploration of the thermal decomposition of oxalates of copper and silver by experimental and computational methods. J Anal Appl Pyrol 120, 207-214.

30. Tao L, Ying L. Guohua M (2017) Guidance Evolution Mechanism of Nickel Oxalate Microstructure for Formation of Polycrystalline Nickel Nano-fibers. Rare Metal Mater Eng 46, 2371-2374.

31. Dong Y, Li X, Liu S, Zhua Q, Li JG, Suna X (2015) Facile synthesis of high silver content MOD ink by using silver oxalate precursor for inkjet printing applications. Thin Solid Films 589, 381-387.

32. Boldyrev VV (2002) Thermal decomposition of silver oxalate. Thermochim Acta 388, 63-90.

33. Dollimore D (1987) The thermal decomposition of oxalates. A review. Thermochim Acta 117, 331-363.

34. Dollimore D (1990) The production of metals and alloys by the decomposition of oxysalts. Thermochim. Acta 177, 59-75.

35. Galwey AK, Brown ME (2007) An appreciation of the chemical approach of V. V. Boldyrev to the study of the decomposition of solids. J Therm Anal Cal (2007) 90, 9-22

36. Małecka B, Drozdz-Ciesla E, Małecki A (2004) Mechanism and kinetics of thermal decomposition of zinc oxalate, Thermochim Acta 423, 13-18

37. Kolezynsk A, Małecki, A (2009) First principles studies of thermal decomposition of anhydrous zinc oxalate. J Therm Anal Cal 96, 645-651; Theoretical studies of thermal decomposition of anhydrous cadmium and silver oxalates. J Therm Anal Cal 96, 161$165 ; 96,167-173$.

38. Kolezynski A (2010) FP-LAPW study of anhydrous cadmium and silver oxalates: electronic structure and electron density topology. Physica B 405, 3650-3657.

39. Kolezynski A, Handke B, Drozdz-Ciesla, E (2013) Crystal structure, electronic structure, and bonding properties of anhydrous nickel oxalate. J Therm Anal Cal 113, 319-328.

40. Puzan AN, Baumer VN, Lisovytskiy DV, Mateychenko PV (2018) Structure disordering and thermal decomposition of manganese oxalate dihydrate, $\mathrm{MnC}_{2} \mathrm{O}_{4} \cdot 2 \mathrm{H}_{2} \mathrm{O}$. J Solid State Chem 260, 87-94. 
41. Puzan, AN, Baumer VN, Lisovytskiy DV, Mateychenko PV (2018) Structure transformations in nickel oxalate dihydrate $\mathrm{NiC}_{2} \mathrm{O}_{4}$. $2 \mathrm{H}_{2} \mathrm{O}$ and nickel formate dihydrate $\mathrm{Ni}\left(\mathrm{HCO}_{2}\right) \cdot 2 \mathrm{H}_{2} \mathrm{O}$ during thermal decomposition. J Solid State Chem 266, 133-142.

42. Stencel R, Kasperski J, Pakieła W, Mertas A, Bobela E, Barszczewska-Rybarek I, Chladek G (2018) Properties of experimental dental composites containing antibacterial silverreleasing filler. Materials 11, 1031-1057.

43. Ferreira JM, Oliveira M, Trindade GF, Santos LCL, Tomachuk CR, Baker MA (2018) Development and characterisation of zinc oxalate conversion coatings on zinc. Corros Sci 137, 13-32.

44. Gabal MA, Ahmed MA (2005) Structural, electrical and magnetic properties of copper-cadmium ferrites prepared from metal oxalates. J Mater Sci 40, 387-398.

45. Chauhan KM, Arora SL (2009) Diamagnetic and photoabsorption characterization of gel-grown cadmium oxalate single crystals, Cryst Res Technol 44, 189-196.

46. Bridle C, Lomer TR (1965) The growth of crystals in silica gel, and the unit-cell dimensions of cadmium oxalate and copper tartrate. Acta Cryst 19, 483-484.

47. Shedam MR, Venkateswara Rao A. (1993) Growth of single crystals of cadmium oxalate in silica gels. Cryst Res Technol 20, K5-K7.

48. Arora SK, Abraham J (1981) Controlled nucleation of cadmium oxalate in silica hydrogel and characterization of grown crystals. Cryst Growth 52, 851-857.

49. Moses Ezhil Raj A, Deva Jayanthi D. Bena Jothy V (2008) Optimized growth and characterization of cadmium oxalate single crystals in silica gel. Solid State Sci 10, 557-562.

50. Dalal PV (2013) Nucleation controlled growth of cadmium oxalate crystals in agar gel and their characterization. Ind J Mater Sci 2003, $1-5$.

51. Prasad NV, Prasad G, Bhimasankaram T, Suryanarayana SV, Kumar GS (1996) Dielectric properties of cobalt doped cadmium oxalate crystals. Bull Mater Sci 19, 639-643.

52. Lin HC, Lin P, Lu CA, Wang SF (2009) Effects of silver oxalate additions on the physical characteristics of low-temperature-curing MOD silver paste for thick-film applications. Microelectron Eng 86, 2316-2319.

53. López MC, Tirado JL, Pérez Vicente C (2013) Structural and comparative electrochemical study of $\mathrm{M}$ (II) oxalates, $\mathrm{M}=\mathrm{Mn}, \mathrm{Fe}$, $\mathrm{Co}, \mathrm{Ni}, \mathrm{Cu}, \mathrm{Zn}$. J Power Sources 227, 65-71.

54. Nacimiento F, Alcántara R, Tirado JL (2010) Cobalt and tin oxalates and PAN mixture as a new electrode material for lithium ion batteries, J Electroanal Chem 642, 143-149.

55. Elijah Ang, WA, Cheah YL, Wong CL, Hng HH, Madhavi S (2015) One-pot solvothermal synthesis of $\mathrm{Co}_{1-\mathrm{x}} \mathrm{Mn}_{\mathrm{x}} \mathrm{C}_{2} \mathrm{O}_{2}$ and their application as anode materials for lithium-ion batteries. J. Alloys Compd 638, 324-333.

56. Xu J, He L, Liu H, Han T, Wang Y, Zhang C, Zhang Y (2015) Controlled synthesis of porous anhydrous cobalt oxalate nanorods with high reversible capacity and excellent cycling stability. Electrochim Acta 170, 85-91.

57. Mathur R, Sharma DR, Vadera SR, Kumar N (2001) Doping of emeraldine base with the monovalent bridging iron oxalate ions and their transformation into nanostructured conducting polymer composites. Acta Mater 49, 181-187.

58. Delogu F (2012) Estimation of the mass of powder trapped at collision during ball milling from the kinetics of the mechanically activated decomposition of Ag oxalate. Mater Chem Phys 137, 297-302; (2014) Mechanochemical decomposition of $\mathrm{Ag}$ and $\mathrm{Ni}$ oxalates. Mater Chem Phys 147, 629-635.

59. Delogu F (2014) Ag-Ni Janus nanoparticles by mechanochemical decomposition of Ag and Ni oxalates. Acta Mater. 66, 388-395.

60. Ligios GA, Bertetto AM, Delogu F. (2013) A systematic investigation of the mechanochemical decomposition of Ag oxalate in rod drop experiments. J Alloys Compd 554 426-431.
61. Alderson A, Alderson KL (2005) Expanding Materials and Applications: Exploiting Auxetic Textiles. Tech Text Int 14, 29-34.

62. Ravirala N, Alderson KL, Davies PJ, Simkins VR, Alderson A (2006) Negative Poisson's Ratio Polyester Fibers. Text Res J 76, 540-546.

63. Ugbolue SC, Kim YK, Warner SB, Fan Q, Yang CL. Kyzymchuk O. Feng Y. (2010) The formation and performance of auxetic textiles. Part I: theoretical and technical considerations. J. Text. Inst. 101, 660-667.

64. Hu H, Wang ZY, Liu S (2011) Development of Auxetic Fabrics Using Flat Knitting Technology. Text. Res. J. 81, 856-863.

65. Wang Z, Hu H (2014) Auxetic Materials and their Potential Applications in Textiles Text. Res. J. 84, 16001611 (2014).

66. Ma ZD, Liu YY, Liu XM, Sun C, Cui Y (2011) Ultralightweight Runflat Tires Based upon Negative Poisson Ratio (NPR) Auxetic Structures. US Pat 2011/0168313A1.

67. Scarpa F, Giacomin J, Zhang Y, Pastorino P (2005) Mechanical Performance of Auxetic Polyurethane Foam for Antivibration Glove Applications. Cell. Polym. 24, 253-268.

68. Dolla W, Fricke BA, Becker BR (2007) Structural and Drug Diffusion Models of Conventional and Auxetic Drug-Eluting Stents. J Med Devices 1, 47-56.

69. Scarpa F (2008) Auxetic Materials for Bioprostheses. IEEE Sign Proc Mag 25, 126-128.

70. Lira C, Scarpa F, Rajasekaran RA (2011) Gradient Cellular Core for Aeroengine Fan Blades Based on Auxetic Configurations. J Intel Mater Syst Str 22, 907-917.

71. Liu Q (2006) Literature Review: Materials with Negative Poisson's Ratios and Potential Applications to Aerospace and Defence. Report DSTO-GD-0472. DSTO Formal Reports, Sidney.

72. Bornengo D, Scarpa F, Remillat C (2005) Evaluation of Hexagonal Chiral Structure for Morphing Airfoil Concept. J Aerosp Eng 219, 185-192.

73. Martin J, Heyder-Bruckner J, Remillat C, Scarpa F, Potter K, Ruzzene M (2008) The Hexachiral Prismatic Wingbox Concept. Phys Stat Sol (b) 245, 570-571.

74. Alderson A, Rasburn J, Ameer-Beg S, Mullarkey PG, Perrie W, Evans KE (2000) An Auxetic Filter: A Tuneable Filter Displaying Enhanced Size Selectivity or Defouling Properties. Ind Eng Chem Res 39, 654-665.

75. Alderson A, Rasburn J, Evans KE, Grima JN (2001) Auxetic Polymeric Filters Display Enhanced De-Fouling and Pressure Compensation Properties. Membr Technol 137, 6-8.

76. Lee JH, Singer JP, Thomas EL (2012) Micro-Nanostructured Mechanical Metamaterials. Adv Mater 24, 4782-4810.

77. Babee S, Shim J, Weaver JC, Chen ER, Patel N, Bertoldi K (2013) 3D Soft Metamaterial with Negative Poisson's Ratio. Adv Mater 25, 5044-5049.

78. Grima JN, Winczewski S, Mizzi L, Grech MC, Cauchi R, Gatt R, Attard D, Wojciechowski KW, Rybicki J (2014) Tailoring Graphene to Achieve Negative Poisson's Ratio Properties. Adv Mater 27, $1455-1459$.

79. Ghaedizadeh A, Shen J, Ren X, Xie YM (2017) Designing Composites with Negative Linear Compressibility. Mater Des 131, 343-357.

80. Perdew JP, Burke K, Ernzerhof M (1996) Generalized Gradient Approximation Made Simple. Phys Rev Lett 77, 3865-3868.

81. Perdew JP, Ruzsinszky A, Csonka GI, Vydrov OA, Scuseria GE, Constantin LA, Zhou X, Burke K (2008) Restoring the DensityGradient Expansion for Exchange in Solids and Surfaces. Phys Rev Lett 100, 136406.

82. Grimme S (2006) Semiempirical GGA-type Density Functional Constructed with a Long-Range Dispersion Correction. J Comput Chem 27, 1787-1799. 
83. Clark SJ, Segall MD, Pickard CJ, Hasnip PJ, Probert MIJ, Refson K, Payne MC (2005) First Principles Methods Using CASTEP. Z Kristallogr 220, 567-570.

84. MaterialsStudio, http://3dsbiovia.com/products/collaborative-science/biovia-materials-studio/ (accessed April 2019).

85. Troullier N, Martins JL (1991) Efficient Pseudopotentials for PlaneWave Calculations. Phys Rev B 43, 1993-2006.

86. Pfrommer BG, Cote M, Louie SG, Cohen ML (1997) Relaxation of Crystals with the Quasi-Newton Method. J Comput Phys 131, 233240.

87. Monkhorst HJ, Pack JD (1976) Special Points for Brillouin-zone Integration. Phys Rev B 13, 5188-5192.

88. Downs RT, Bartelmehs KL, Gibbs GV, Boisen MB (1993) Interactive Software for Calculating and Displaying X-Ray or Neutron Powder Diffractometer Patterns of Crystalline Materials. Am Mineral 78, 1104-1107.

89. Yu R, Zhu J, Ye HQ (2010) Calculations of Single-Crystal Elastic Constants Made Simple. Comput Phys Commun 181, 671-675.

90. Birch F (1947) Finite Elastic Strain of Cubic Crystal. Phys Rev 71, 809-824.

91. Angel RJ (2000) Equations of State. Rev Mineral Geochem 41, 35-60. EOSFIT 5.2 software, http://www.ccp14.ac.uk/ccp/ webmirrors/ross-angel/rja/soft/.10.2138/rmg.2000.41.2 (accessed May 2019)

92. Marmier A, Lethbridge ZAD, Walton RI, Smith CW, Parker SC, Evans KE (2010) ElAM: A Computer Program for the Analysis and Representation of Anisotropic Elastic Properties. Comput Phys Commun 181, 2102-2115.

93. Kondrashev YD, Bogdanov VS, Golubev SN, Pron GF (1985) Crystal structure of the ordered phase of zinc oxalate and the structure of anhydrous $\mathrm{Fe}^{2+}, \mathrm{Co}^{2+}, \mathrm{Ni}^{2+}, \mathrm{Cu}^{2+}$ and $\mathrm{Zn}^{2+}$ oxalates. $\mathrm{J}$ Struct Chem 26, 74-77.

94. Jeanneau E, Audebrand N, Louer D (2011) $\beta-\mathrm{CdC}_{2} \mathrm{O}_{4}$. Acta Cryst C 57, 1012-1013.

95. Virovets AV, Naumov DY, Boldyreva EV, Podberezskaya NV (1993) Structure of lead(II) oxalate dihydrate. Acta Cryst C 49, $1882-1884$.

96. Puzan AN, Baumer VN, Vashchenko VV, Sofronov DS (2017) Polymorphism of anhydrous cadmium oxalate $\mathrm{CdC}_{2} \mathrm{O}_{4}$. J Alloys Compd 726, 751-757.

97. Weck PF, Kim E, Buck EC (2015) On the Mechanical Stability of Uranyl Peroxide Hydrates: Implications for Nuclear Fuel Degradation. RSC Adv 5, 79090-79097.

98. Voigt W (1962) Lehrbuch der Kristallphysik. Teubner, Leipzig.

99. Reuss A (1929) Berechnung der Fliessgrenze von Mischkristallen auf Grund der Plastizitatsbedingung fur Einkristalle. Z Angew Math Mech 9, 49-58.

100. Hill R (1952) The Elastic Behaviour of a Crystalline Aggregate. Proc Phys Soc Lond A 65, 349-354.

101. Colmenero F, Bonales LJ, Cobos J, Timón V (2017) Structural, Mechanical and Vibrational Study of Uranyl Silicate Mineral Soddyite by DFT Calculations. J Solid State Chem 253, 249-257.

102. Colmenero F, Bonales LJ, Cobos J, Timón V (2017) Thermodynamic and Mechanical Properties of Rutherfordine Mineral Based on Density Functional Theory. J Phys Chem C 121, 5994-6001.

103. Colmenero F, Cobos J, Timón V (2018) Periodic DFT Study of the Structure, Raman Spectrum and Mechanical Properties of Schoepite Mineral. Inorg Chem 57, 4470-4481.

104. Colmenero F, Fernández AM, Cobos J, Timón V (2018) Becquerelite Mineral Phase: Crystal Structure and Thermodynamic and Mechanic Stability by Using Periodic DFT. RSC Adv 8, 2459924616.

105. Colmenero F, Plášil J, Cobos J, Sejkora J, Timón V, Čejka J, Bonales LJ (2019) Crystal structure, hydrogen bonding, mechanical properties and Raman spectrum of the lead uranyl silicate monohydrate mineral kasolite. RSC Adv 9, 15323-15334.

106. Colmenero F. Theoretical Studies of the Structural, Mechanical and Raman Spectroscopic Properties of Uranyl-Containing Minerals. In: Essa KS (ed) Minerals. InTechOpen, London. ISBN: 978-953-516784-6.

107. Born M (1940) On the Stability of Crystal Lattices. I. Math Proc Camb Phil Soc 36, 160-172.

108. Mouhat F, Coudert FX (2014) Necessary and Sufficient Elastic Stability Conditions in Various Crystal Systems. Phys Rev B 90 , 224104.

109. Pugh SF (1954) XCII. Relations between the Elastic Moduli and the Plastic Properties of Polycrystalline Pure Metals. Phil Mag 45, 823-843.

110. Bouhadda Y, Djella S, Bououdina M, Fenineche N, Boudouma Y (2012) Structural and Elastic Properties of $\mathrm{LiBH}_{4}$ for Hydrogen Storage Applications. J Alloys Compd 534, 20-24.

111. Niu H, Wei P, Sun Y, Chen CX, Franchini C, Li D, Li Y (2011) Electronic, Optical, and Mechanical Properties of Superhard ColdCompressed Phases of Carbon. Appl Phys Lett 99, 031901.

112. Ranganathan SI, Ostoja-Starzewski M (2008) Universal Elastic Anisotropy Index. Phys Rev Lett 101, 055504.

113. Ranganathan SI, Murshed MR, Costa L (2018) Heterogeneous Anisotropy Index and scaling in two-phase random polycrystals. Acta Mech 229, 2631-2646.

114. Lethbridge ZAD, Walton RI, Marmier ASH, Smith CW, Evans KE (2010) Elastic Anisotropy and Extreme Poisson's Ratios in Single Crystals. Acta Mater 58, 6444-6451.

115. Lakes RS, Wojciechowski KW (2008) Negative Compressibility, Negative Poisson's Ratio and Stability. Phys Stat Sol (b) 245, 545551.

116. Grima JN, Caruana-Gauci R (2012) Mechanical metamaterials: Materials that push back. Nat Mater 11, 565-566.

117. Keskar NR, Chelikowsky JR (1992) Negative Poisson's Ratios in Crystalline $\mathrm{SiO}_{2}$ from First-Principles Calculations. Nature 358, 222-224.

118. Grima JN, Gatt R, Alderson A, Evans KE (2006) An Alternative Explanation for the Negative Poisson's Ratios in $\alpha$-Cristobalite. Mater Sci Eng A 423, 219-224.

119. Grima JN, Gatt R, Zammit V, Williams JJ, Evans KE, Alderson A, Walton RI (2007) Natrolite: A Zeolite with Negative Poisson's Ratios. J Appl Phys 101, 086102.

120. Coudert FX (2016) Systematic Investigation of the Mechanical Properties of Pure Silica Zeolites: Stiffness, Anisotropy, and Negative Linear Compressibility. Phys Chem Chem Phys 18, 9079 9087.

121. Coudert FX (2017) Predicting the Mechanical Properties of Zeolite Frameworks by Machine Learning. Chem Mater 29, 7833-7839.

122. Yao YT, Alderson KL, Alderson A (2016) Modeling of Negative Poisson's Ratio (Auxetic) Crystalline Cellulose $I_{\beta}$. Cellulose 23, 3429-3448

123. Tan JC, Civalleri B, Erba A, Albanese E (2015) Quantum Mechanical Predictions to Elucidate the Anisotropic Elastic Properties of Zeolitic Imidazolate Frameworks: ZIF-4 vs. ZIF-zni. CrystEngComm 17, 375-382.

124. Ryder MR, Tan JC (2016) Explaining the Mechanical Mechanisms of Zeolitic Metal-Organic Frameworks: Revealing Auxeticity and Anomalous Elasticity. Dalton Trans 45, 4154-4161.

125. Sun H, Mukherjee S, Singh CV (2016) Mechanical Properties of Monolayer Penta-Graphene and Phagraphene: A First-Principles Study. Phys Chem Chem Phys 18, 26736-26742.

126. Du Y, Maassen J, Wu W, Luo Z, Xu X, Ye PD (2016) Auxetic Black Phosphorus: A 2D Material with Negative Poisson's Ratio. Nano Lett 16, 6701-6708. 
127. Li W, Probert MR, Kosa M, Bennett MTD, Thirumurugan A, Burwood RP, Parinello M, Howard JA, Cheetham AK (2012) Negative Linear Compressibility of a Metal-organic Framework. J Am Chem Soc 134, 11940-11943.

128. Qiao Y, Wang K, Yuan H, Yang K, Zou B (2015) Negative Linear Compressibility in Organic Mineral Ammonium Oxalate Monohydrate with Hydrogen Bonding Wine-Rack Motifs. J Phys Chem Lett 6, 2755-2760.

129. Coates CS, Makepeace JW, Seel AG, Baise M, Slater B, Goodwin AL (2018) Synthesis, PtS-type Structure, and Anomalous Mechanics of the $\mathrm{Cd}(\mathrm{CN})_{2}$ Precursor $\mathrm{Cd}\left(\mathrm{NH}_{3}\right)_{2}\left[\mathrm{Cd}(\mathrm{CN})_{4}\right]$. Dalton Trans 47, 7263-7271.

130. Marmier A, Ntoahae PS, Ngoepe PE, Pettifor DG, Parker SC (2010) Negative Compressibility in Platinum Sulfide Using DensityFunctional Theory. Phys Rev B 81, 172102.

131. Kang L, Jiang X, Luo S, Gong P, Li W, Wu X, Li Y, Li X, Chen C, Lin $Z$ (2016) Negative Linear Compressibility in a Crystal of $\alpha-$ $\mathrm{BiB}_{3} \mathrm{O}_{6}$. Sci. Rep. 5, 13432.

132. Dagdelen J, Montoya J, De Jong M, Persson K (2017) Computational Prediction of New Auxetic Materials. Nat Commun $8,323$.

133. Ho DT, Park SD, Kwon SY, Park K, Kim SY (2014) Negative Poisson's Ratios in Metal Nanoplates. Nat Commun 5, 3255.

134. Wu D, Wang S, Zhan S, Yuan SJ, Yang B, Chen H (2018) Highly Negative Poisson's Ratio in a Flexible Two-Dimensional Tungsten Carbide Monolayer. Phys Chem Chem Phys 20, 18924-18930.

135. Hao F, Liao X, Li M, Xiao H, Chen X (2018) Oxidation-Induced Negative Poisson's Ratio of Phosphorene. J Phys: Cond Matter 30, 315302.

136. Wang H, Li Q, Gao Y, Miao F, Zhou XF, Wan XG (2016) Strain Effects on Borophene: Ideal Strength, Negative Possion's Ratio and Phonon Instability. New J Phys 18, 073016.

137. Wang H, Zhang ZD, Wu RQ, Sun LZ (2013) Large-Scale FirstPrinciples Determination of Anisotropic Mechanical Properties of Magnetostrictive Fe-Ga Alloys. Acta Mater 61, 2919-2925.

138. Wang H, Li X, Li P, Yang J (2017) $\delta$-Phosphorene: A TwoDimensional Material with High Negative Poisson's Ratio. Nanoscale 9, 850-855.

139. Wang XF, Jones TE, Li W, Zhou YC (2012) Extreme Poisson's Ratios and their Electronic Origin in B2 CsCl-type AB Intermetallic Compounds. Phys Rev B 85, 134108.

140. Yalameha S, Vaez A (2018) Ab-Initio Thermodynamic and Elastic Properties of AlNi and AlNi Intermetallic Compounds. Int J Mod Phys B 32, 1850129.

141. Hsueh HC, Lee CC, Wang CW, Crain J (2000) Compression Mechanisms in the Anisotropically Bonded Elements Se and Te. Phys Rev B 61, 3851-3856.

142. Ren W, Ye JT, Shi W, Tang ZK, Chan CT, Sheng P (2009) Negative compressibility of Selenium chains confined in the channels of zeolite singe crystals. New J Phys 11, 103014. 